\title{
New Directions in Language Center Direction
}

\author{
Margaret Gonglewski \\ George Washington University \\ John Angell \\ University of Louisiana at Lafayette \\ Stayc DuBravac \\ Florida Atlantic University
}

Language laboratories, and the paradigm that they represent, may soon be a thing of the past, not because they are being cut, but rather because they are being renamed 'Language Centers'. Underlying this deceptively simple name change is an evolving shift in conceptualizations of what it means to learn or know a language and in the availability of tools we use to implement these new visions. Indeed, language centers are-or can bekey elements of a transformed pedagogy of language that complements changes in best classroom practice by using media and technologies to scaffold student learning. In other words, while content-based, student-centered and contextualized communicative language practice have supplanted aunique focus on guided repetition or memorization of form for form's sake alone, the language lab construct has proven resistant to a similarly substantive evolution. As a result, language center directors regularly find themselves in the delicate position of trying to influence how their teaching assistants and colleagues use their centers while simultaneously managing the centers' technical and human resources to meet these new demands.

The language lab mentality among administratorsand students sometimes proves equally resistant to change. An additional complication for center directors is that, beyond changing the sign on the door from laboratory to center and altering how stakeholders are willing to use the facilities, center directors and instructors charged with enacting this expanding mandate may not always have a clearly articulated, concrete vision of what these new language centers can be or how the vision can be implemented. This predicament can lead to professional 
frustration, unused or underused facilities, and stagnant relationships with language departments.

The presenters, three language center directors recently charged with managing the lab-to-center transition, came to this topic in a somewhat roundabout manner. As foreign language faculty in French and German, the three of us met at national academic conferences and, realizing we shared common interests in several areas, we collaborated on several projects on topics such ascreative writing in foreign language teaching and the effective integration of technology in language instruction. Each of us put technology to use in our institutions, but it was not until we moved into positions heading up language centers that we began to grapple with the issues we hope to address in this presentation. In talking to each other, we realized the common thread across our jobs - the expectations, the demands, the challenges - of changing labs to centers, and we were inspired to trace the theoretical roots motivating the change in the profession as a whole. At the same time, we wanted the opportunity to demonstrate how three centers (and center directors) with similar visions, created different expressions of this vision, given our diverse resources, levels of responsibility and support.

In our session, we describe how we are meeting this challenge of transforming centers and ensuring their effective use by colleagues and departments. We first review what we perceive to be the principal pedagogical, administrative, and practical stakes. We then outline some of the potential advantages that this transformation holds for the language teaching profession. As directors of language centersstriving to encourage and assist teaching personnel in moving beyond behavioristic practices associated with the lab paradigm, we also relate difficulties we have encountered promoting a broader vision among administrators, students, and teachers. For example, some instructors and students persist in using our centers solely or primarily as labs, i.e., for electronic workbook exercises, audio materials, for example, and, many continue to view the center as a place for beginning-level language only. Some even resist the namechange! Notsurprisingly, students tend to mirror their instructors' sometimes implicit, sometimes explicit predilection for low-risk, often mechanistic practices such as drills and workbookexercises as opposed to more exploratory or dialogic uses of media and tools such as computer mediated communication and creative projects. 


\section{Gonglewski, Angell and DuBravac}

We begin the presentation by providing a general overview of the specific theoretical principles that have initiated the transformation from 'labs' to 'centers', including ashift towards learner autonomy, reflective practice in learning and teaching, and the growing emphasis on community in the language classroom. We include a discussion of task-types that we believe characterize sound practice in communicative use of electronic media and show that differences among users' theoretical assumptions about language learning are not necessarily in binary opposition (i.e., communicative or not communicative) but may be complementary. In other words, we believe there are subtle as well as overt changes in how centers are used that can contribute to better use of both human and technical resources.

Oursession will also address practical factors impinging on the shift from lab to center, such as student learning styles and familiarity with multiple technologies, current capabilities of technology specific to language learning, and the ubiquitous problem of diminishing resources. We will outline how each of us has approached the design of physical and virtual space, direction of activities and support, staffing, supervising and coordinating among various language sections and levels. We also describe our individual approaches to publicizing our centerstomake them complement, enrich, and enhance language program missions, while using the available technologies in order to avoid unnecessary expenses on resources that are used infrequently or not at all. As a crucial step in demonstrating the diverse manifestations that new 'centers' can encompass, each of the three presenters will engage in a personal narrative of the complexion and particularities of his/her respectivesituation, stressing how local circumstances have an impact on the change from lab to center. Where possible, we will provide examples of changes we initiated (e.g., before and after photographs, statistics).

We will conclude the presentation with a discussion of concrete ideas for facilitating the evolution from 'laboratory' to 'center'.

These include:

1) Education/training: we discuss approaches to teaching instructors or directors in appropriate use of technology that is already available;

2) Hiring staff: we present practices for defining positions and efficiently training and using staff to support the director's vision of the center; 
3) Language course coordination issues: we offer counsel for coordinating multiple languages and including upper-division courses as well as lowerdivision courses;

4) Space issues: we explore the connection between the spatial construction or arrangement of a center and its use, and we offer strategies for moving toward a more constructivist use of the language center.

5) Resource-building and outreach: we propose ideas for connecting with local groups in mutually beneficial arrangements that build on use the existing strengths of the center.

This panel focuses on the experience of the three presenters in their respective institutional contexts; however, throughout the panel, the presenters aim to foster discussion with audience members regarding their own struggles and successes in this area. We believe that our most valuable resource, along the path from laboratory to center, are other center directors working in similar contexts towards similar goals.

Notsurprisingly, transforming language laboratories tocenters is a topic that colleaguesare beginning toaddressin professional circles. In a recent article (2004), Peter Liddell and Nina Garrett ${ }^{1}$ identify goals for new centers and features that these centers have in common. The goals they list include points such as validating language teaching and learning across the curriculum, providing new resources and expertise for the support of language programs, and supporting the integration of technology intolanguage learning and teaching. They continue by stating that the important features that thesecenters have in common are technology, key relations with stakeholder departments, academic leadership, and focus on research and SLA. We discuss how we have managed to address many of the goalsstated above and include some personal goals that we had for our particular centers. The discussion includes how features mentioned by Liddell and Garrett play a role in our transformation from language lab to language center. •

Note

'Liddell, P. and N. Garrett. 2004. "The new language centers and the role of technology: New mandates, new horizons." InNewperspectives on CALL forsecond languageclassrooms. Edited by S. Fotosand C. Brown. Mahwah, NJ:Lawrence Erlbaum Associates. 